\title{
Research on the Integration and Development of Internet Piano Teaching and Traditional Piano Teaching
}

\author{
Zhang Ning ${ }^{1}$, Li Jia ${ }^{2, *}$ \\ ${ }^{1}$ Shanxi Vocational College of Art, Taiyuan, Shanxi 030012, China \\ ${ }^{2}$ College of Music,Shanxi Normal University, Shanxi, China \\ *Corresponding author: lijia@sxnu.edu.cn
}

\begin{abstract}
Under the background of the comprehensive deepening of quality education in China, piano has become the main choice for most parents to improve their children's artistic temperament, which also promotes the development of piano education in China. In the context of Internet, the disadvantages of traditional piano teaching mode are gradually exposed, which seriously restricts the improvement of piano teaching level. In the new era, the development of all sectors of society is inseparable from the application of Internet technology, not to mention the field of education and teaching. Piano teaching is also deeply influenced by Internet technology and gradually embarks on the road of upgrading and transformation, in the process of which, however,relevant personnel need to realize that there are still many advantages that can not be ignored in traditional piano teaching. We can not blindly pursue internet teaching and completely abandon traditional teaching. Only by organically combining the two can we really promote the reform of piano teaching. In view of this, this paper mainly analyzes the drawbacks of traditional piano teaching and Internet piano teaching. Meanwhile, the advantages and strategies of their integration are discussed to enlighten relevant personnel.
\end{abstract}

Keywords: Internet piano teaching; Traditional piano teaching; Fusion strategy

\section{Introduction}

With the continuous progress of people's educational awareness, people pay more and more attention to the cultivation of students' comprehensive quality. Due to the dispensable status of Piano course to cultivate students' musical literacy and aesthetic taste, many parents are inclined to ask their children to learn piano. On the other hand, the teaching methods adopted by teachers who insist on traditional apporoaches are too single and rigid, mainly based on teachers' explanation and demonstration and students' mechanical practice, are not conducive to students' emotional integration and then affect students' piano learning effect. With the advent of the Internet era, many new educational technologies and means have emerged in piano teaching, greatly enriching the content and form of piano teaching, bringing a new experience for students' piano learning and effectively improving students' piano learning ability. Nevertheless, both traditional teaching and internet teaching have their own advantages and disadvantages. If the two can be integrated and complementary, the best teaching effect can be achieved. Therefore, relevant personnel should attach greater importance to and strengthen research on this aspect.

\section{Disadvantages in traditional piano teaching}

\subsection{Insufficient teaching of theoretical knowledge}

The learning of any discipline needs the support of theoretical knowledge and the internalization of practical operation, and theory and practice are interrelated and complementary. Neither of them is indispensable, otherwise it will affect the learning effect. In traditional piano teaching, however, some teachers are deeply influenced by traditional educational ideas, which result in a bad consequence that they put too much focus on piano practical teaching and relatively ignore the teaching of theoretical knowledge. Even in the early stage of teaching, they let students practice piano and require students to play simple piano music [1]. However, without the support of theoretical knowledge, students can only practice the piano mechanically and lack the ability of independent learning and self-improvement. As a result, although many students can play musical instruments, they lack essential cognition of the most 
basic theoretical knowledge, which limits the improvement of students' piano learning ability.

\subsection{Unreasonable teaching objectives}

Stimulating students' interest in piano learning is an important goal in piano teaching, because interest is the key factor to promote students' learning motivation. Only when students establish emotion with piano art, will they have a strong interest in piano learning and show high enthusiasm and initiative in piano learning. In this way, it can not only ensure the effect of students' piano learning, but also make the process of students' emotional learning more relaxed and pleasant so that the students will be interested in piano learning. However, in terms of the current setting of piano teaching objectives, most teachers' teaching objectives will focus on the cultivation of students' piano playing skills and abilities, and the cultivation of students' learning interest is relatively ignored. As a result, teachers will only let students master corresponding playing skills and methods through mechanical training in the teaching process. Little attention is paid to students' emotional changes in learning. Thus, in such piano teaching, it is difficult for students to be happy in piano learning. Even worse, students will take piano learning as a burden, which will affect students' interest in piano learning.

\subsection{Boring teaching content}

Many students complain that the process of piano learning is very boring, and the reason for this phenomenon is not only related to the improper teaching methods of teachers, but also related to the teachers' failure to use the teaching materials creatively. Piano teaching content is the practice of some piano music scores. If the teacher only explains the subject according to the book and asks the students to practice repeatedly according to the music scores, it will make the classroom teaching atmosphere boring and unattractive, reducing the students' interest in piano learning [2]. However, if teachers can creatively use teaching materials according to the actual situation and needs of students and provide students with diversified piano learning contents, they can effectively mobilize students' piano learning enthusiasm and promote students' personalized development.

\section{Advantages and disadvantages of Internet Piano Teaching}

\subsection{Advantages of Internet piano teaching}

In traditional piano teaching, the teaching resources used are very limited and the sharing of teaching resources is also very poor, which affects the effect of piano teaching. In the context of the Internet, teaching resources can be shared in time through the Internet platform, which will effectively enrich piano teaching resources. And there are many online resources about piano teaching on the Internet. Teachers and students can obtain them at any time with the help of the Internet, so as to facilitate the piano learning of students. At the same time, in piano teaching, the resource-sharing function of the Internet can be used to send some piano learning resources to students, which breaks the regional and spatio-temporal limitations in traditional piano teaching and broadens the space for students' Piano Learning [3]. In addition, teachers can also use the interactive function of the Internet to establish a good interactive relationship with students and solve puzzles encountered in piano learning for students anytime and anywhere so that the effect of students' piano learning will be effectively improved.

\subsection{Disadvantages of Internet Piano Teaching}

Piano learning has an obvious feature that students' learning will enter a continuous stage. In this stage, only under the guidance and supervision of teachers and on the basis of students' repeated drills and speculation, can the knowledge be assimilated. Then, students will master a relatively perfect knowledge structure and learning system. However, internet teaching has higher requirements for students' autonomous learning ability. Teachers' supervision over students is relatively weakened, which makes it difficult for some students to train continuously, and then affects the improvement of students' piano learning ability. In addition, in traditional classroom teaching, teachers timely find the disadvantages of students in playing and correct them, so that students can have a clear direction of practice. However, in the context of the Internet, they will search for piano teaching videos on the Internet for learning while encountering problems. Due to the insufficient diagnostic ability of some students and the poor quality of online teaching resources, students are more likely to embark on the wrong training path, which affects the improvement of students' piano learning level. 


\section{Advantages of integration of Internet piano teaching and traditional piano teaching}

\subsection{Expanding the teaching content}

Traditional piano teaching takes textbooks as the main teaching content and basis. The learning resources that students can access are very limited, which affects the expansion of students' learning vision and limits the further improvement of students' piano learning ability. And the traditional piano teaching content lacks diversity, which is difficult to meet the needs of students for personalized and diversified learning. However, traditional piano teaching materials are professional and authoritative that ensure the quality of students' piano practice [4]. At present, there are many kinds of piano teaching resources on the Internet, including music scores, teaching videos of famous teachers and so on. If these teaching resources are introduced into classroom teaching, the piano teaching content will be enriched. However, the professionalism of online teaching resources is far less than that of traditional piano teaching materials. Therefore, while using online teaching resources, teachers must choose teaching materials carefully, and take online resources as a beneficial extension and expansion of traditional piano teaching contents.

\subsection{Improving the teaching quality}

In traditional piano teaching, teachers mostly give specific guidance on students' playing ability face to face, so that students will accurately master the corresponding playing skills. However, due to certain limitations of traditional teaching methods, it is difficult for teachers to effectively supervise students' after-school exercises, resulting in uncontinous practice of some students. In order to solve this problem, teacers can take advantage of the internet to make up for the disadvantages of traditional piano teaching and effectively supervise students' after-school training [5]. For example, after assigning tasks to students on various network platforms or software platforms, teachers will supervise and guide students' afterschool learning by requring students to upload their practice to the platform. In addition, depending on the intuitiveness of internet, some abstract piano theoretical knowledge are shown through pictures, videos and other intuitive ways. It will facilitate students' understanding and mastery of knowledge, strengthen students' learning effect, and effectively improve the quality of piano teaching.

\section{Approaches of integration of Internet piano teaching and traditional piano teaching}

\subsection{Using internet technology to extend traditional piano teaching}

In traditional piano teaching, students' piano learning mainly depends on teachers' explanations and demonstrations. In this process, students must rely on their own memory to master methods and skills and internalize these knowledge and playing skills through repeated training. Meanwhile, most students are unable to maintain their attention in class for a long time due to the influence of various objective factors, resulting in their failure to remember and understand knowledge points or problems in time. Moreover, they will encounter some difficulties in practice. However, because of the limited teaching time in the classroom, teachers can't find them in time and effectively solve the problems existing in students' performance, resulting in some students' failure to understand the teaching content thoroughly, which affects the learning effect of students [6]. In order to solve this problem, teachers introduce internet teaching means into piano teaching to realize the extension and supplement of traditional piano teaching, and strengthen students' piano learning effect. For example, before class, teachers can make classroom teaching contents and practice tracks into micro-class videos and upload them to online learning platforms or wechat group, so that students can download and preview by themselves. In the process of previewing, students can record their unsolved problems or puzzles, so as to facilitate targeted listening in class and ensure the efficiency of listening. In classroom teaching, teachers can simplify some abstract and difficult knowledge points with the help of various advanced network teaching tools and means, so that students can easily understand and master them. Moreover, some novel online teaching resources can also be introduced to attract students' attention and motivate students' learning enthusiasm. After class, teachers can upload the teaching resources used in classroom teaching and after-class tasks to the learning platform, so that students can download the materials according to their actual situation to solve their problems in time. Then, the learning effect will be strengthened. 


\subsection{Using internet technology to optimize piano teaching environment}

Piano is a very elegant art. Piano performance often bring people auditory enjoyment and spiritual pleasure, which is also an important factor for most students to become interested in piano learning. However, in the traditional piano teaching, teachers rarely show students the charm of piano. Instead, they put too much emphasis on the teaching of performance skills and methods, which makes students boring to have a repeated training. It is difficult for students to have fun in the process of piano learning. Over time, students will gradually lose interest in piano learning. Moreover, in the long-term passive training, students will not realize the elegance of the piano and form an auditory enjoyment. They also input less emotion in piano performance so that the music they play naturally lacks appeal [7]. In order to solve this problem, teachers can introduce internet teaching, which will create a good piano learning environment, make students feel the charm of piano, and then effectively mobilize students' enthusiasm and initiative in piano learning. For example, in classroom teaching, teachers can download some piano playing videos from the network and play them with the help of multimedia equipment, so that students will feel the elegance and beauty of the piano in the beautiful melody. This will also stimulate students' interest in learning the teaching content. At the same time, in the teaching of piano playing skills, the previous "preaching" and "indoctrination" teaching methods are changed. Teacheruse internet technology to play different piano melodies and visualize the music, which is convenient for students to understand and master these skills, and motivate students' enthusiasm in piano learning.

\subsection{Using Internet technology to strengthen after-school counseling for students}

From the above analyses, we know that these disadvantages of traditional piano teaching mainly show up as the lack of after-school counseling. At present, Internet technology has been popularized and applied in thousands of households. Under the background of the Internet, most families are equipped with networks and computers. This also provides convenience for piano teachers' after-school counseling. During effective classroom teaching time, it is difficult for students to fully understand and master the teaching content, and it is hard to skillfully play a track. In order to solve this problem, teachers can establish a good interaction with students with the help of Internet technology, and guide students' afterschool exercises through online communication. At the same time, students feed back their problems to teachers in time and ask teachers for help. Meanwhile, teachers can assign some piano practice tasks, let students take videos of their performance process, and then upload them to the internet. Teachers can supervise students' after-school practice by watching their videos, then comment and guide students' piano laraning, so as to ensure the effect of students' after-school practice. In addition, teachers can encourage students to properly use online learning resources after class and learn more about piano performance, which will expand their knowledge. Furthermore, teachers can recommend some excellent piano learning resources to students through WeChat and Weibo, and let students do contrast exercises, so as to improve students' piano learning level.

\section{Conclusion}

To sum up, in the new era, traditional piano teaching methods gradually expose some disadvantages. It is hard to meet the needs of current piano teaching. The emergence of Internet technology provide more plentiful contents and tools for piano teaching and realize the optimization and innovation of traditional piano teaching. However, internet teaching has some disadvantages. Only by organically combining traditional teaching with internet teaching can the level of piano teaching be truly improved and students' piano learning become more efficient and relaxed.

\section{References}

[1] Mu Jianyun. A brief discussion on the practice of "Internet+" in Piano Teaching in Colleges and Universities [J]. Appreciation, 2021(08):96-98.

[2] Cai Chang. Discussion on the application of network teaching in traditional piano teaching [J]. Song of The Yellow River, 2020(18):42-43.

[3] Guo Renjie. Integration and development of Internet piano teaching and traditional piano teaching [J]. Yi Shu Da Guan, 2020(11):78-79.

[4] Liu Xiaodong. Discussion on the integration and development of Internet piano teaching and traditional piano teaching [J]. Artists of China, 2019(06):212.

[5] Wang Yingli,Pan baichuan. Discussion on the integration and development path of Internet piano 
Frontiers in Art Research

ISSN 2618-1568 Vol. 3, Issue 8: 77-81, DOI: 10.25236/FAR.2021.030813

teaching and traditional piano teaching [J]. Northern Music, 2019,39(01):247-248.

[6] Yu Yang. Analysis on the integration and development of Internet piano teaching and traditional piano teaching [J]. Appreciation, 2018(30):287-288.

[7] Liang Shihan. Discussion on the integration and development of Internet piano teaching and traditional piano teaching [J]. Participation Flowers, 2018(01):122. 